\title{
Introduction to the inaugural collection
}

\author{
Xiaohe Lu • Kit-Chun Joanna Lam
}

Published online: 28 May 2011

(C) Springer Science+Business Media B.V. 2011

Its seems that the world is moving out of the shadow of financial crisis, but the causes leading to the financial crisis still deserve our reflections. It is worth exploring the role of capital, credit, and corporate social responsibility in wealth creation. How to explore these issues using the resources of economics, business and ethics, and incorporating theoretical, institutional, and normative issues are of common concerns to researchers in China and many other countries. For this purpose, the Center for Business Ethics of Shanghai Academy of Social Sciences organized the Third Shanghai International Conference on Business Ethics in collaboration with the Shanghai Association of Ethics, the Shanghai Association of Economics, the University of St. Thomas of USA, and the Euro-China Centre for Leadership and Responsibility at CEIBS. The theme was "Capital, Credit, and Responsibility in Crisis: What Concepts, Systems, and Ethics are needed for Future Wealth Creation?" More than 70 prominent academics and business practitioners attended the conference, including overseas scholars from USA, France, Germany, Norway, Switzerland, Belgium, Holland, South Africa, and Japan; and scholars and practitioners from China including Hong Kong, Beijing, Hunan, Henan, Wuhan, Jiangsu, Guangzhou, and Shanghai.

During the 2-day conference, participants had enthusiastic discussions around the two major themes of the conference: capital, credit, and responsibility in crisis, business ethics reflections on the financial crisis; and the concepts, systems, and ethics needed for future wealth creation. There were eight sessions altogether, including a roundtable with prominent business practitioners as speakers. Local and international scholars had in-depth analyses of capital, credit, corporate social responsibility, and the causes of the financial crisis from the perspective of business ethics. The concepts, systems, and ethics needed for future wealth creation were also

X. Lu ( $\triangle)$

Shanghai Academy of Social Sciences, Shanghai, China

e-mail: 1xh@sass.org.cn

K.-C. J. Lam

Hong Kong Baptist University, Hong Kong, China

e-mail: kclam@hkbu.edu.hk 
studied. There were more than 50 papers and 40 topics on wealth, capital and ethics, wealth creation, civil society and people's well-being, wealth creation, and corporate social responsibilities. Some of the studies were theoretical and some empirical.

After the financial crisis, a lot of research and discussions have occurred done on the causes of the crisis. In the first session of our conference, researchers provided some reflections and analyses of the financial crisis from the angle of business ethics. Professors M.A. Santoro, Xiaohe Lu, Peter Koslowski, Dajian Xu, and Hongwu Qiao presented papers on "Ethical Breakdown of Governance of the U.S. Financial System," "Financial Crisis and Capital Credit," "Financial Wagers and Hyper-Speculation," "The Ethical Nature and Limitations of Financial Regulation," and "Responsibility Ethics and the Prevention of Financial Crises." They put forward many new ideas and perspectives to analyze the roots of the financial crisis, including the collapse of morality in the financial system, virtual production, gambling attitudes, and rational illusion. There were also important suggestions concerning how institutions and codes of ethics can be constructed based on the consideration of ethics and responsibility.

The second session turned to the second major theme of the conference. It started with a discussion on the topic "Post-Credit Crisis: What new Concepts are Needed?" Three scholars from the University of St. Thomas organized this session. They criticized some old notions and practices, and proposed some new concepts and ideas. For example, Daryl Koehn suggested that we cannot rely on the concept of Corporate Social Responsibility (CSR) to save morality after the financial crisis. The key to control risk and to prevent crises is to educate and strengthen the professional responsibility of companies and their high-level management.

Since the emergence of business ethics, the relationship between business and ethics has always been the concern of academia and practitioners. After the financial crisis, their concern goes into greater depth concerning the relationships between wealth and ethics, capital and ethics. New concepts are needed for future wealth creation, and it is important for us to re-think about these relationships. In the third session, Professor KaiLin Tang and other Chinese scholars had discussions around the topic "Wealth, Capital and Ethics," including how business ethics is possible in the age of capital, moral capital and its economic value, morality of capital and its accomplishment, and the meaning of the ethical dimensions of wealth for the growth of wealth. Participants believed that ethical norms are needed for wealth creation and capital utilization, and called for further clarification and in-depth analyses of these issues both in terms of concepts and practices.

Wealth creation, capital utilization, and economic development are taking place in civil societies. The basic purpose of these activities should be the well-being of people. Scholars put forward many constructive concepts and ways of thinking on this theme. In the fourth session "Wealth Creation, Civil Society and People's WellBeing," Professor Marwen Brown put forward a new concept on civilizing wealth creation. Professors Lanfen $\mathrm{Li}$ and Pinyue $\mathrm{Lu}$ respectively discussed the theme around topics on the distribution of wealth, transformation of the mode of economic development, citizen responsibility, and the construction of a just international financial system.

In the second day of the conference, participants' discussions turned to the actors of wealth creation in the corporate level. How do corporations consider future wealth 
creation? What roles and responsibilities should these corporations take? The fifth session is a Roundtable on "Capital, Credit and CSR." Mr. Guorong Fen, president of Shanghai Shenying \& Wanguo Security Company, Mr. Xizhen Wu, executive president of Henan Lingrui Pharmaceutical Company, Mr. Li Yuan, president \& general manager of Fuda Group Ltd., and Mr. Peter Buytaert, president \& CEO China Global Leaders, Pudong introduced their practices and experience on major issues of business ethics and corporate responsibility in the course of development of their companies, such as issues related to the transformation of the mode of economic development and the restructuring of private enterprises. They shared with the conference participants their knowledge and understanding of corporate responsibility, followed by heated discussions among enthusiastic participants.

Corporate responsibility and related issues for the future of enterprises in wealth creation are not only issues that entrepreneurs need to think about and put into practice, but have also been the research focus of academics for the last 30 years. After the financial crisis, how do scholars think about these issues? In the sixth session "Wealth Creators: CSR and Integrity: Lessons and Experiences," Professor H.W. Høivik introduced to participants the way in which Norwegian small and medium-sized enterprises have incorporated CSR into their business strategies actively after the financial crisis to respond to social demand for corporate responsibility. Japanese scholar Toru Umeda argued that corporate governance gaps should be narrowed both by CSR and by governmental regulations; Professor Jue Wang and other Chinese scholars made presentations on the differentiated structure of CSR in China, examining and evaluating in order CSR, CSR and regulation and senior executives' high pay during the financial crisis; Professor H. C. de Bettgnies at CIBES presented his views on the problems and prospects of CSR in China.

In the financial crisis, what is the role of the subject of business ethics? What lessons can we learn from it? In the seventh session, based on the development of business ethics from the past 30 years, especially the challenges to business ethics in the financial crisis, Professor Xiuyi Zhao raised three issues which have to be clarified for business ethics; Swiss scholars A. Reisner, P. Hess, and T. B. Hodel explored the relationship between the teaching of business ethics and wealth creation; Professor GJ Rossouw from South Africa provided a global report on "Capitalism, Finance and Corporate Responsibility: the Impact of the Global Financial Crisis of 2008." These topics had drawn great interest and active discussions from the conference participants.

The final objective of the international conference was to improve the study and practice of business ethics in China. The theme of the last session of the conference was "Wealth Creation and Practical Ethical Issues in China". Scholars from China and other countries presented in-depth studies and discussions of various business ethics issues in the course of the development of the Chinese economy. Professor Georges Enderle discussed the experiences of wealth creation and the lessons from the perspective of development ethics. Professors from Hong Kong-Kit-Chun Lam and Pak-Wai Liu compared the structure of trust in China and USA, and found empirically that the structure of trust in people and trust in corporations are different between the two countries, which may be due to their differences in economic and institutional backgrounds. Professor Zhaoming Gao of Nanjing Normal University 
gave an ethical analysis of land bonuses and a reflection on ways of wealth creation in contemporary China. Other scholars gave reviews of economic and business ethics in China, including training, teaching, and research.

Xiaohe Lu and Daryl Koehn chaired the closing ceremony of the conference. Neil Olivier, the representative of the world renowned publisher Springer Science+ Business Media, attended the whole conference. He informed the participants that year 2012 will mark the 30th anniversary of the Journal of Business Ethics. It was announced in the 2nd Shanghai International Conference on Business Ethics that Springer will publish a new specialized journal-the Asian Journal of Business Ethics. He noted that there is a demand for this journal as the discipline of business ethics develops, and this is something scholars are looking forward to. Now that the journal is open for online submission, he would like to solicit support from conference participants. Yiqin Yang, the editor of Moralization and Civilization - the journal of the Association of Ethics in China, also expressed a wish for the journal to get connected to the world through this conference, so that the journal can become a platform for the exchange between the Association of Ethics in China and the world, and a window for the world to understand the construction of morality and ethics and related research in China.

This conference was a high-level international conference. The conference was held in the post-financial crisis period. It provided some open and forward-looking research topics, and drew enthusiastic interest from many prominent business ethicists within China and from all over the world, including ethicists, economists, and business practitioners. Participants provided high-quality research and presentations on topics related to the conference themes, including issues related to future wealth creation and various problems related to the well-being of people. We hope that we can further our international cooperation and exchange in the future so that we can better deal with crisis, facilitate economic growth, and contribute to the development of theory and practice of business ethics.

After the conference, the editor-in-chief of the Journal of Business Ethics and the new Asian Journal of Business Ethics-Professor Alex Michalos, suggested that selected papers from the conference be published in a Special Inaugural Issue of the Asian Journal of Business Ethics which will appear in the year 2012. He invited $\mathrm{Xiaohe} \mathrm{Lu}$ to serve as the guest editor of the special issue, and the co-editor of AJBE, Kit-Chun Joanna Lam to serve as a co-editor of this special issue. At the same time, Georges Enderle, Daryl Koehn, and Henri Claude were invited to serve on the review team to do blind reviews of articles for AJBE. After 3 months of review and revision of articles, six articles were finally accepted and are now published in this special issue. Alex could not attend the conference, but he had read all articles in English carefully before the conference, had provided leadership in the entire review process, and also served as a reviewer. We sincerely thank Springer, Neil, Alex, and the three members of the review team. We would also like to thank all the conference participants for their support. Without this new international journal, the guidance of Alex, the hard work of the review committee, the understanding and support of the conference organizers and conference participants, we could not have completed this Special Inaugural Issue successfully. It is our wish that the Asian Journal of Business Ethics will gain recognition and influence in the future. 